\title{
Analysis of the Needham Puzzle and Its Modern Value
}

\author{
Xin XU \\ China Jiliang University \\ College of Humanities \& Foreign Languages \\ Zhejiang, Hangzhou, China \\ jiliangxuxin@126.com
}

\begin{abstract}
Needham problem' is a question about Chinese modern science and technology put forward by British famous scientist and science historian Joseph Needham in 1964. There are various expressions about this problem, among which it is generally accepted that in the long history from the first century BC to the fourteenth century AD, China was far ahead of other countries in the world in terms of science and technology, but why did the scientific and technological revolution of modern history not take place in China? The Needham problem has high academic value and practical significance. This paper will further analyze and discuss the Needham problem and its modern value.
\end{abstract}

Keywords-Needham puzzle; Modern value; Social consciousness

\section{INTRODUCTION}

As one of the four ancient civilizations in the world, China has a splendid history and culture of science and technology, among which the four great inventions have promoted the development and progress of western science and technology. However, after 1840, the level of science and technology in China began to decline, and the development of science and technology in western countries got a qualitative leap. In this regard, the famous British Dr. A difficult question was mentioned in Needham paper The Grand Titration: "Why did modern science develop vigorously only in European countries, while China, where scientific and technological achievements have been far ahead of other countries, has not produced an industrial revolution?" This is what academia calls the 'Needham problem'. 'Needham problem' has attracted the attention of people from all walks of life in the society. Many scholars have studied and answered this question in depth. This problem has helped China to set up a banner to study the Chinese ancient science and technology civilization, and to urge more Chinese and foreign scholars to devote themselves to the research work of ancient Chinese science and technology civilization, which has contributed important practical value.

\section{THE PHENOMENON OF "NEEDHAM PUZZLE"}

In Joseph Needham view, Chinese ancient organic theory and the mechanics determinism and physics determinism in the West are two different scientific paradigms. With the continuous innovation and perfection of science and technology in the future, the "paradigm" will change to a certain extent. The Needham problem effectively promoted the research and development of the history of science and technology and the history of culture in ancient China. It was not just about why there was no scientific revolution in modern China. Denied the scientific and technological achievements created by the Chinese nation [1]. In the author opinion, Joseph Needham raised this question on the contrary in order to oppose Western centrism, on the other hand, to shift scientists ' gaze from the west to the east and to realize the transition from Western determinism to ancient Chinese organic theory. The "Needham Puzzle" has attracted many scientists ' interest in research since it was proposed. For example, famous physicist Oppenheimer, founder of reality change theory Tom, and founder of dissipative structure theory, Prigazin, have all turned their attention from western technology to eastern technology. Through the study of ancient Chinese science and technology civilization to absorb certain nutritional value. The phenomenon of western scientists shifting their attention from the west to the east is called "Needham" phenomenon by the science and technology circles.

\section{NEEDHAM'S INTERPRETATION OF THE PROBLEM}

After putting forward the "Needham problem", Needham himself expounded his own views on the issue. He thought that the main reasons why China did not produce modern science included three aspects. They are Modern Chinese political system, social economy and geography. In the political system, China was influenced by the traditional bureaucratic system, which seriously hindered the formation of the value of social mercantilism. The state failed to attach importance to the integration of folk craftsman technology with the technology invented by scientific scholars. As a result, Chinaundefineds scientific and technological civilization has stalled. On the other hand, the western capitalist system is more conducive to the development of science and technology, thus producing the culture of the industrial revolution and promoting the development of science and technology and commerce. 
Needham believed that Chinaundefineds failure to promote the development of modern science and technology was due to the fact that modern Chinese society failed to attach importance to the development of commerce and industry, and that the status of businessmen was relatively low. Due to the existence of large tracts of unopened land in China, which is more suitable for the development of agricultural activities, the state advocates vigorously developing agricultural activities and neglects the overseas trade and cultural exchanges with other countries.

\section{THE RESTRICTION OF THE IMPERIAL EXAMINATION SYSTEM IN MODERN CHINA}

For the solution of Needham problem, Yang Zhenning, the famous physicist Nobel laureate in China, attributed its cause to the imperial examination system of the Qing Dynasty. In his opinion, in China's modern history, it has always been resistant to western scientific and technological culture, and there are only moral, humanistic and social structure theories in the traditional culture of modern society. To a certain extent, the research and development of science and technology thinking and natural philosophy have been neglected, and the unitization of imperial examination system has seriously restricted peopleundefineds innovative thinking, and the development of science and technology cannot be separated from the innovation of education. Under the Imperial examination system of Qing Dynasty, the outstanding talents of the country were often served by the supreme ruler. They are perusal in literature, moral and ethical, but lack of deep research spirit of natural science, under this system culture will seriously hinder the development of modern science and technology, the country is difficult to cultivate innovative comprehensive talent. As we all know, based on the Imperial examination system, the social education mode is to inculcate the traditional culture knowledge with the private school teachers, the students are always in the passive learning state, lack the ability to think and innovate and practice ability, these will affect the innovation and development of the national science and technology.

\section{The InFLUENCE OF ANCIENT CONFUCIAN CULTURE}

In "Needham problem", some scholars take the ancient Chinese Confucian culture as the breakthrough point to analyze the problem in detail, and put forward their own explanation point of view [2]. For example, Yi Fang and Jiang Jiexia once mentioned in "Joseph Needham's Problem Solving - Concurrently Discussing the Prerequisites of the 21st Century Scientific and Technological Revolution", that the reason why there was no scientific and technological revolution in modern China was because of the influence of the traditional Confucian culture. The core of the traditional Confucian cultural thought is "heart, understanding, knowing heaven". In the relation between man and nature, Confucian culture neglects the relationship between subject and object, and fails to analyze and understand from the angle of natural science. This will affect the development of national natural science. In addition, the traditional Confucian ideology and culture attach too much importance to moral ethics and emphasize that the country should vigorously develop ethical and moral culture, which leads to the extreme of "pan-morality" in modern China. In ancient China, it was the Mohist culture that really advocated the development of natural science and paid more attention to practice. However, it failed to get the attention of the state court, which led to the disappearance of the latter culture.

\section{COMPREHENSIVE UNDERSTANDING OF CHINESE HISTORY AND CORRECT UNDERSTANDING OF ANCIENT SCIENCE AND TECHNOLOGY CIVILIZATION}

The research significance of "Needham" problem is not only to find the correct answer, but also to discover the modern value in the course of the research, and to sum up the advantages and disadvantages of the development process of Chinese science and technology. From the contrast with the western science and technology development to obtain more enlightening significance, to promote more people to understand Chinaundefineds ancient science and technology history and culture. Among the four ancient civilizations of mankind, only the Chinese people in modern times are the descendants of the creators of ancient Chinese civilization. In this long history and culture, as Chinese people must understand the ancient history and culture. Proud of the science and technology invented by the ancestors. [3] It is helpful for more scholars at home and abroad to discover and understand the development process of science and technology in ancient China, and to sort out and classify ancient Chinese history and culture by carrying out in-depth research and discussion on the "Needham problem". Comparing with the history and culture of science and technology in western countries, the author sums up the advanced experience of science and technology development and promotes the further development of national science and technology level. In addition, studying the problem of "Needham" is also helpful to promote the development of patriotic education, to make more correct understanding of the factors that affect the development of science and technology civilization, to obtain the enlightening significance from it, and how to create new scientific and technological civilization in the new period.

\section{IDENTIFYING THE DIRECTION OF FUTURE DEVELOPMENT AND DRAWING ON THE OUTSTANDING DEVELOPMENT EXPERIENCE OF THE WEST}

Science and technology as one of the important criteria for evaluating the comprehensive strength of a country, we should correctly recognize the importance of developing science and technology, and at the same time avoid repeating the mistakes of the western scientific and technological powers while obtaining the welfare from the development of science and technology innovation. Technology can change lives as well as bring about negative disasters. Through the deep study of Needhamundefineds difficult problem, the world can understand the splendid history and culture of ancient China, correctly understand the relationship between man and nature, develop and utilize science and technology as reasonably as possible, and make clear the development direction of science and technology in the future. In the era of economic globalization, if we want to maintain our competitiveness with developed countries and realize the great rejuvenation of the 
Chinese nation, we must actively draw on the excellent experience of western scientific and technological development and re-examine our own civilization. Strengthen exchanges and cooperation with Western cultures. The study of "Needham problem" is one of the important ways to reexamine the Chinese civilization. We should analyze the factors that hinder the development of science and technology in modern China from various angles, and make a comparative analysis with the development of science and technology in the west. To fully understand the differences between Chinese and Western science and technology civilization, what advantages and disadvantages have been created in the traditional Chinese civilization will affect the stable development of the country in the future [4]. The study of "Needham" problem can help the Chinese to better review our historical civilization, gain more historical experience and help modern China find a way to modernization.

\section{REALIZING THE DEVELOPMENT OF MODERN SCIENTIFIC INNOVATION AND CONSTRUCTING A NEW SCIENTIFIC PARADIGM}

With the continuous passage of time, the development of social science in the $21 \mathrm{st}$ century is in urgent need of constructing a brand-new scientific paradigm so as to achieve stable and sustainable development of science. The formation of the western ancient scientific thought promoted the generation of modern science and technology, so what kind of influence will the ancient Chinese science and technology civilization have on the development of modern science and technology, and how to promote it. The proposition of "Needham" problem makes more and more scientists at home and abroad have strong interest in Chinese traditional culture. Each scholar tries to find out the way to solve this problem from the content of Chinese ancient organic view of nature. The essence of modern scientific thought is to replace determinism with organic theory, but the traditional determinism in western countries can not meet the demand of modern scientific development. Therefore, it is possible to realize the innovation and development of modern science and construct a new scientific paradigm by deeply studying the difficult problem of "Needham" and effectively absorbing the organic theory thought in the ancient Chinese view of nature. The modern value of the Needham problem lies in introducing the development of scientific thought from western determinism to Chinese organic theory. It can fully excavate the modern scientific value of Chinese traditional science civilization, promote the great change of modern science, and create great value contribution.

\section{CONCLUSION}

In summary, the modern value of the study of Needham problem lies in absorbing the experience value from it, summing up the advantages and disadvantages of the history of science development between China and the West, so long as the conditions for scientific development are obtained, a new scientific civilization can be created. To construct a new scientific paradigm. There are many negative reasons for the backwardness of Chinaundefineds modern scientific level. We should draw lessons, sum up experience and believe that through continuous efforts, Chinaundefineds scientific and technological level will rise to a higher level in the future.

\section{REFERENCES}

[1] Hong Xiaonan. From the perspective of ancient Chinese science and technology culture, see "Needham Problem" Chinese Culture Monthly [J]. 2015 (03): 65-68.

[2] Zhang Chuncheng. Origin, Phenomenon, and Scientific Value of Needham Problem [J]. Journal of Henan University(Social Science), 2013(05):121-123.

[3] LI Yong. Exploring the "Needham Problem"---Reflected from the Perspective of Traditional Chinese Thinking Mode [J]. Journal of Ezhou University, 2015 (4):56-57.

[4] Yi Fang, Jiang Jiexia. "Needham Problem" Solution --- also on the Premise of the 21st Century Science and Technology Revolution [J]. Journal of Social Sciences of Xiangtan University: 2015(5):30-32. 